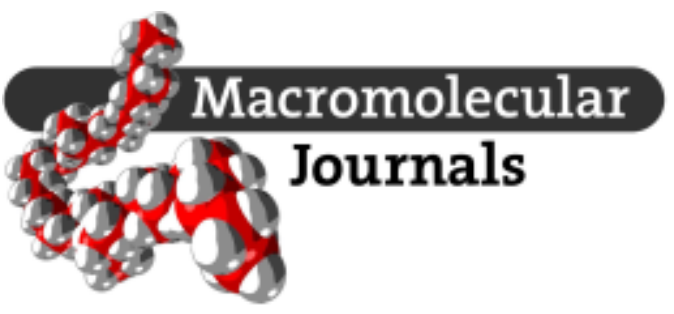

Dear Author,

Please correct your galley proofs carefully and return them no more than four days after the page proofs have been received.

The editors reserve the right to publish your article without your corrections if the proofs do not arrive in time.

Note that the author is liable for damages arising from incorrect statements, including misprints.

Please note any queries that require your attention. These are indicated with a $Q$ in the PDF and a question at the end of the document.

Please limit corrections to errors already in the text; cost incurred for any further changes or additions will be charged to the author, unless such changes have been agreed upon by the editor.

Reprints may be ordered by filling out the accompanying form.

Return the reprint order form by fax or by e-mail with the corrected proofs, to WileyVCH : macromol@wiley-vch.de
Postfach 101161 69451 Weinheim Germany WILEY-VCH

Courier services:

Boschstraße 12

69469 Weinheim

Germany

Tel.: (+49) 6201606581

Fax: (+49) 6201606510

E-mail: macromol@wiley-vch.de

To avoid commonly occurring errors, please ensure that the following important items are correct in your proofs (please note that once your article is published online, no further corrections can be made):

- Names of all authors present and spelled correctly

- Titles of authors correct (Prof. or Dr. only: please note, Prof. Dr. is not used in the journals)

- Addresses and postcodes correct

- E-mail address of corresponding author correct (current email address)

- Funding bodies included and grant numbers accurate

- Title of article OK

- All figures included

- Equations correct (symbols and sub/superscripts)

Corrections should be made directly in the PDF file using the PDF annotation tools. If you have questions about this, please contact the editorial office. The corrected PDF and any accompanying files should be uploaded to the journal's Editorial Manager site. 


\section{COMMUNICATIONS}

Q1 $\begin{array}{lll}1 & x x x x\end{array}$

F. Zhao, A. Bonasera, U. Nöchel, M. Behl, D. Bléger*... 1700527

Reversible Modulation of Elasticity in Fluoroazobenzene-Containing Hydrogels Using Green and Blue Light

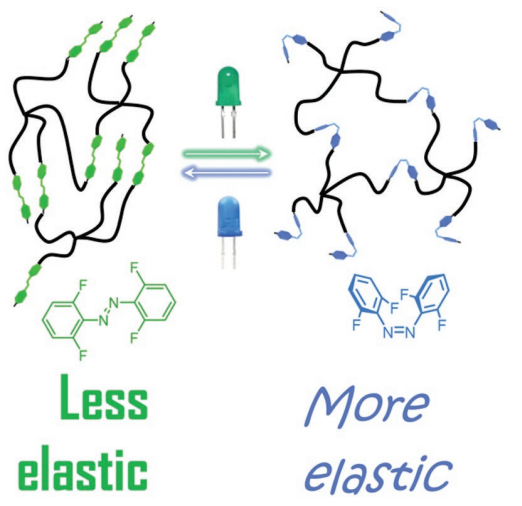

Phototuning hydrogels' mechanical prop- 1 erties with visible light are achieved by incorporating all-visible azobenzene derivatives within PEGylated networks.

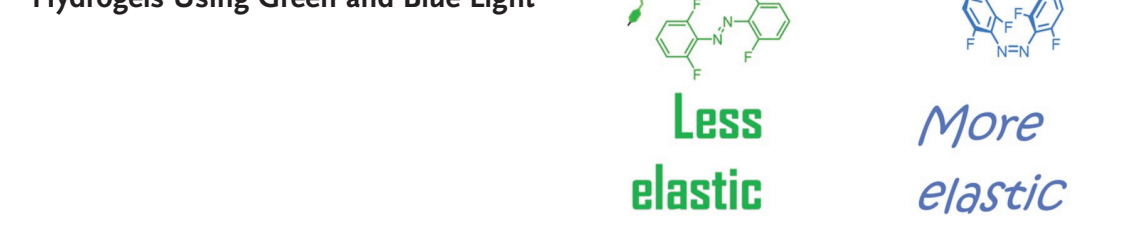




\title{
Reversible Modulation of Elasticity in Fluoroazobenzene- Containing Hydrogels Using Green and Blue Light
}

\author{
Fangli Zhao, Aurelio Bonasera, Ulrich Nöchel, Marc Behl, and David Bléger*
}

Hydrogels are soft materials that have found multiple applications in biomedicine and represent a good platform for the introduction of molecular switches and synthetic machines into macromolecular networks. Tuning their mechanical properties reversibly with light is appealing for a variety of advanced applications and has been demonstrated in the past; however, their activation typically requires the use of UV light, which displays several drawbacks related to its damaging character and limited penetration in tissues and materials. This study circumvents this limitation by introducing all-visible ortho-fluoroazobenzene switches into a hydrophilic network, which, as a result, can be activated with green or blue light. Photoisomerization of the photochromic moieties is accompanied by a reversible tuning of the elastic modulus. The translation of molecular isomerization within the network into macroscopic modulation of its mechanical properties is attributed to different aggregation tendencies of the $E$ and $Z$ isomers of the azobenzene derivatives.
Gels are especially sensitive to their 10 environment and can be designed to 11 readily respond to variations in, typically, 12 $\mathrm{pH}$ or temperature. ${ }^{[5]}$ Light is another 13 trigger of choice offering the advantage 14 of precise photopatterning ${ }^{[4]}$ and allows 15 to alter hydrogels' mechanical properties 16 either permanently by implementing photo- 17 cleavable groups ${ }^{[6]}$ or reversibly using 18 photochromic molecules, such as spiro- 19 pyrans $^{[7,8]}$ or azobenzenes. ${ }^{[9]}$ Following 20 the latter strategy, noncovalent physical 21 gels typically lead to materials with light- 22 induced sol-gel transitions, ${ }^{[10-13]}$ whereas 23 covalent chemical gels can exhibit more 24 finely tuneable phenomena such as pho- 25 toinduced motion, ${ }^{[14-18]}$ or softening/ 26 hardening. Photoswitchable hydrogels 27 exhibiting modulation of their mechanical 28 properties have been described;[16,19] how- 29

\section{Introduction}

Hydrogels are 3D networks with high water content that have found many applications in modern medicine, e.g., biomedical implants, adhesives, contact lenses, or scaffolds for tissue engineering. ${ }^{[1]}$ Their mechanical properties, in particular the elasticity, are essential and hence a key parameter is the shear elastic modulus $\left(G^{\prime}\right)$, with different applications requiring moduli across the $10^{2}-10^{7}$ Pa range. ${ }^{[2]}$ For instance, stem cells are known to remember past mechanical environments and differentiate depending on the elastic modulus of the substrate. ${ }^{[3]}$ Hence, creating hydrogels whose elasticity can be tuned on demand is promising for inducing environmental mechanical variations that mimic the extracellular matrix dynamics and dictate cells' fate. ${ }^{[4]}$

F. Zhao, Dr. A. Bonasera, Dr. D. Bléger

Department of Chemistry and IRIS Adlershof

Humboldt-Universität zu Berlin

Brook-Taylor-Str. 2, 12489 Berlin, Germany

E-mail: david.bleger@chemie.hu-berlin.de

Dr. U. Nöchel, Dr. M. Behl

Institute of Biomaterial Science and Berlin-Brandenburg Center

for Regenerative Therapies (BCRT)

Active Polymers Department

Helmholtz-Zentrum Geesthacht

Kantstraße 55, 14513 Teltow, Germany

The ORCID identification number(s) for the author(s) of this article can be found under https://doi.org/10.1002/marc.201700527.

DOI: $10.1002 /$ marc.201700527 ever, their activation requires UV light, which displays several drawbacks related to its damaging character for the materials and its surrounding, as well as its limited light penetration. ${ }^{[20]}$

Here, we present a polyethylene glycol (PEG) hydrogel 33 incorporating ortho-fluoroazobenzenes ${ }^{[21]}$ as cross-linkers (see F4-azo-PEG; Figure 1) and exhibiting reversible photomodulation of elasticity using blue and green light. Ortho-fluoroazobenzenes (abbreviated to F-azos in the following) were selected as photochromic moieties due to their full addressability with visible light and very high thermal stabilities of the thermodynamically less stable $Z$-isomers. F-azos were functionalized in para-positions with amide linkers, since such electron withdrawing groups maximize the separation of $E$ and $Z$ isomers' $\mathrm{n} \rightarrow \pi^{*}$ bands in the visible region ${ }^{[22]}$ (see Figure $2 \mathrm{a}$ ) and hence promote higher photoisomerization yields using blue $(Z \rightarrow E)$ or green $(E \rightarrow Z)$ light.

\section{Results and Discussion}

F4-azo-PEG gel samples were prepared via strain-promoted click cycloaddition between a tetra-armed PEG macromonomer $\left(M_{\mathrm{n}}=10 \mathrm{~kg} \mathrm{~mol}{ }^{-1}\right)$ terminated with azide groups aza-dibenzocyclooctynes $^{[23,24]}$ (F4-azo-bis-DBCO). This reac- 54 tion typically exhibits fast kinetics at room temperature and 55 does not necessitate the presence of a Cu-catalyst, which 56 might be beneficial for the formation of the gel, since once the 57 gelation starts, diffusion of the reactants is reduced. The two 58 starting materials were dissolved in stoichiometric amount in 59 (tetra-N3-PEG) and the F-azo derivative functionalized with 53 

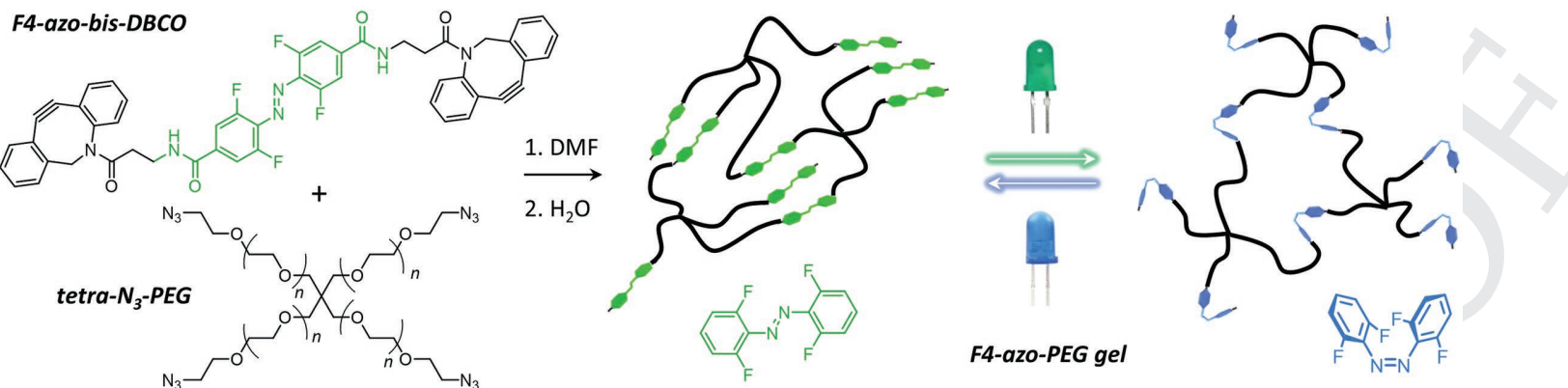

Figure 1. Design and synthesis of photochromic hydrogels responsive to green and blue (LED) irradiation.
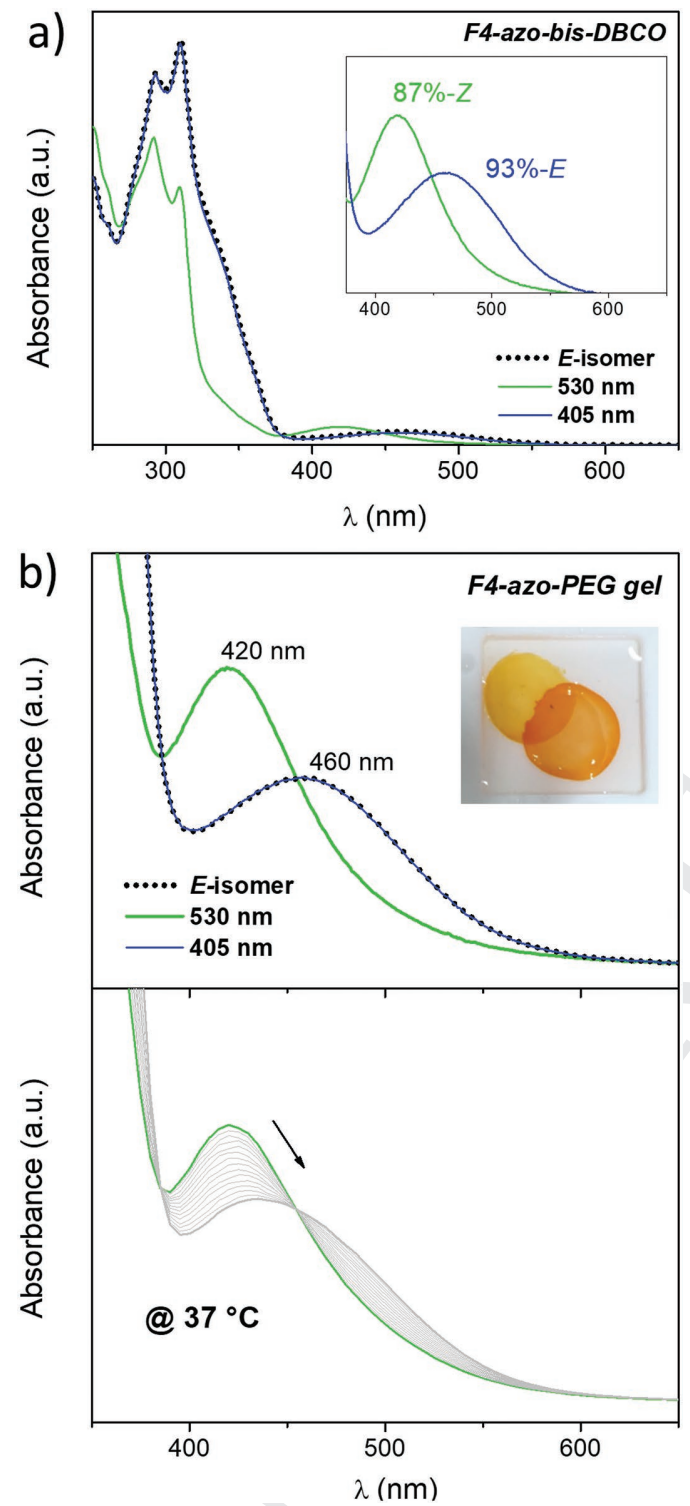

Figure 2. UV-vis absorbance spectra. a) F4-azo-bis-DBCO in acetonitrile at $25^{\circ} \mathrm{C}\left(5.5 \times 10^{-5} \mathrm{~mol} \mathrm{~L}^{-1}\right)$; the inset shows the $\mathrm{n} \longrightarrow \pi^{*}$ bands and indicates the compositions of the PSS mixtures (as determined by liquid chromatography) upon irradiation with visible light. b) F4-azo-PEG gel in water at $25{ }^{\circ} \mathrm{C}$ (top, $\lambda_{\max }$ are indicated next to the curves; the inset highlights the photochromism of the hydrogels) and thermal $Z \rightarrow E$ relaxation at $37^{\circ} \mathrm{C}$ (bottom, each curve was taken with $4 \mathrm{~h}$ interval; total measurement time: $60 \mathrm{~h}$ ). The inset shows the redshift of the $n \rightarrow \pi^{*}$ band over time.
DMF in a disc-shaped mold and stirred at room temperature for $\approx 3 \mathrm{~min}$. When the solution became viscous, the stirring bar was removed and the gel was kept at room temperature for $1 \mathrm{~h}$, followed by $4 \mathrm{~h}$ at $45{ }^{\circ} \mathrm{C}$ in order to obtain homogenous samples. After cooling to room temperature, solvent exchange with distilled water for $3 \mathrm{~d}$ yielded fully swollen hydrogel samples.

The photoisomerization of the F-azo moieties within F4-azoPEG hydrogel samples was investigated by UV-vis spectroscopy (see Figure 2b) and compared with the starting material (F4-azo-bis-DBCO) in solution (see Figure 2a). As typically observed for F-azo derivatives, ${ }^{[21]}$ the green-light-induced $E \rightarrow Z$ isomerization is characterized by a blueshift of the $n \rightarrow \pi *$ band from 460 to $420 \mathrm{~nm}$, while subsequent blue-light irradiation almost completely recovers the initial E-isomer spectrum. This reversible $Z / E$ isomerization can be repeated for several cycles without photobleaching (see Figure $3 \mathrm{~b}$ ). Based on very similar absorption spectra of the hydrogels and F4-azo-bis-DBCO in solution, it can be concluded that photoisomerization within the gel is not hindered and similar photostationary states (PSS) are obtained, i.e., $87 \%$ of Z-isomer and $93 \%$ of E-isomer upon green-light and blue-light irradiation, respectively (see Figure $\mathrm{S} 1$, Supporting Information). The kinetics of the thermal $Z \rightarrow E$ relaxation was then measured at $37{ }^{\circ} \mathrm{C}$. After irradiation with green light until reaching the Z-rich PSS, spectral changes were monitored in the dark (see Figure 2b, bottom). After $60 \mathrm{~h}$, the $\mathrm{n} \rightarrow \pi^{*}$ band experienced a redshift of $15 \mathrm{~nm}$, corresponding to a decrease of $\approx 30 \%$ of $Z$-isomer (from $87 \%$ to $57 \%$ ). Such a slow thermal relaxation, corresponding to a thermal half-live of $\approx 15 \mathrm{~d}$ at $37^{\circ} \mathrm{C}$, is characteristic of F-azos and similar to the free derivatives in solution. ${ }^{[22]}$ The absence of significant acceleration of the $Z \rightarrow E$ thermal isomerization compared to the free molecules in solution indicates that no large mechanical strain is generated within the polymer chains of the networks upon $E \rightarrow Z$ photoisomerization.

Dynamic time sweep rheological experiments were con- 49 ducted to monitor the response of F4-azo-PEG gel in situ 50 upon exposure to visible light. The shear moduli were 51 recorded after $2 \mathrm{~h}$ of equilibration in water with the hydrogel 52 sample loaded into the rheometer. The moduli were measured 53 for frequencies ranging from 0.001 to $100 \mathrm{~Hz}$ at a constant 54 shear strain of $1 \%$ (see Figure S3, Supporting Information). 55 Over this frequency range, the storage modulus $\left(G^{\prime}\right)$ was 56 larger than the loss modulus $\left(G^{\prime \prime}\right)$, indicating a preponder- 57 ance of the elastic behavior within the samples and demon- 58 strating successful cross-linking (in a liquid or melt $G^{\prime}<G^{\prime \prime}$ ). 59 


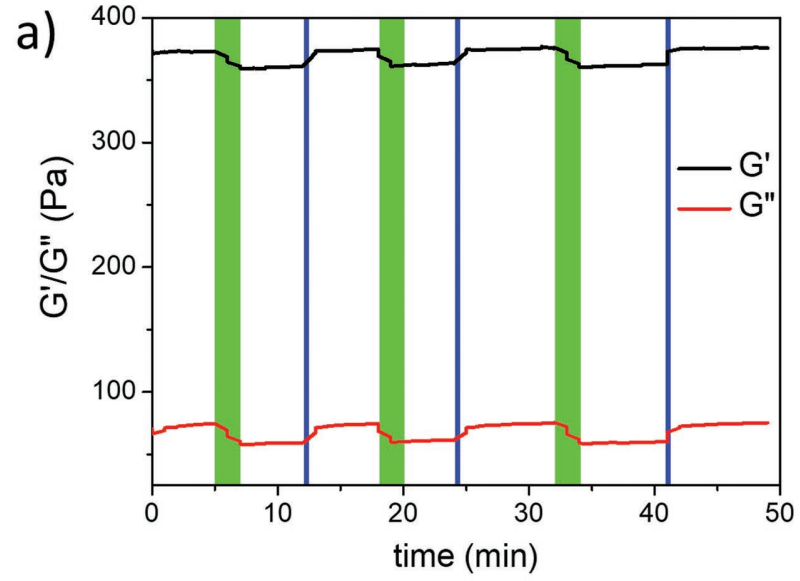

c) DMSO

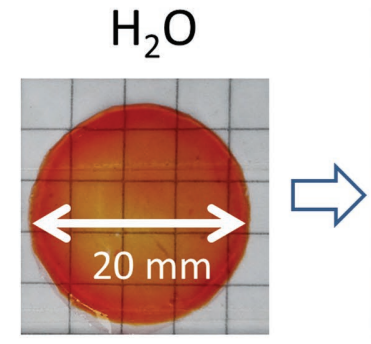

height $=0.6 \mathrm{~mm}$

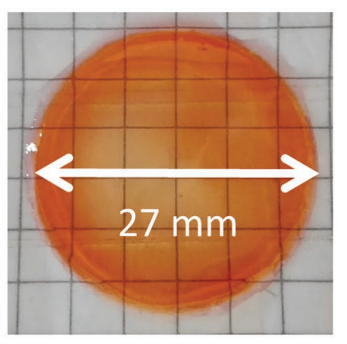

height $=0.7 \mathrm{~mm}$ b)
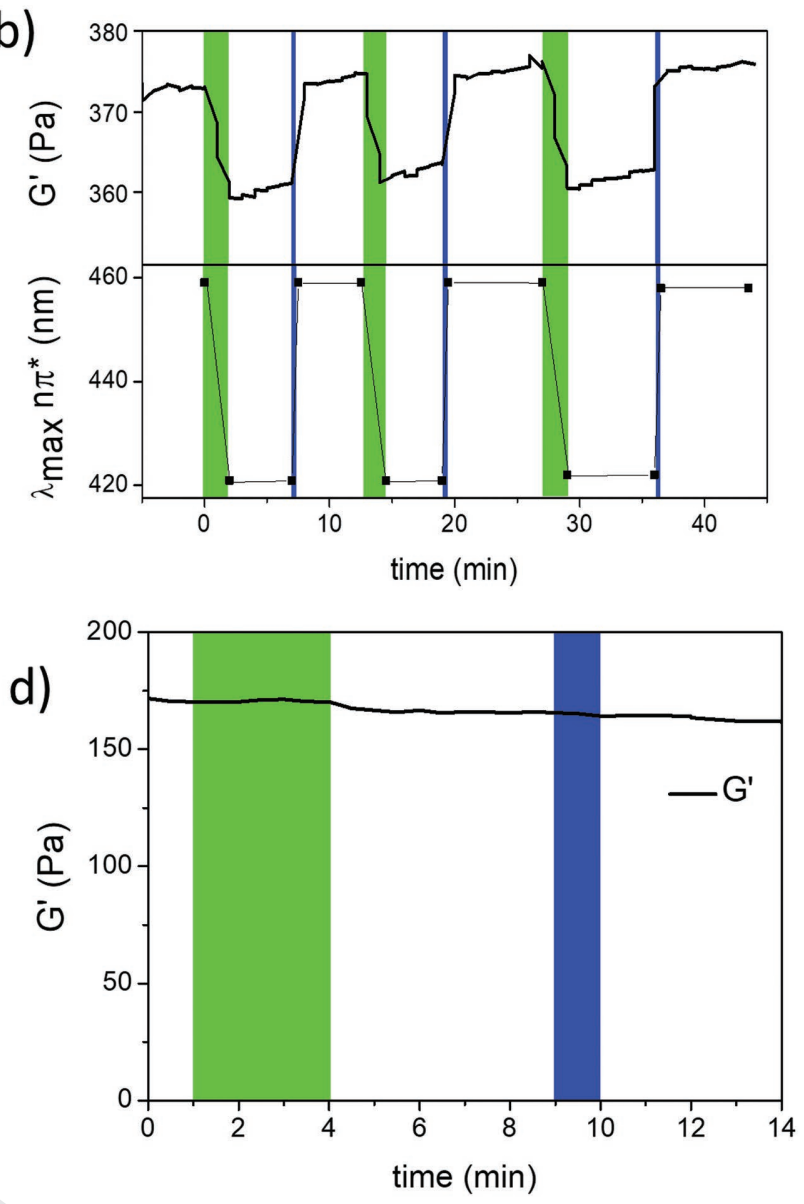

1

Figure 3. Rheology of F4-azo-PEG hydrogel. a) Cyclic changes in $G^{\prime}$ and $C^{\prime \prime}$ obtained upon alternating irradiation with green (530 nm, $\left.2 \mathrm{~min}\right)$ and 33 blue $(405 \mathrm{~nm}, 30 \mathrm{~s})$ LEDs. b) Zoom-in of the $G^{\prime}$ curve (top) and corresponding spectral changes recorded within the same time period (bottom, 34 absorption maxima have been connected with a line to guide the eyes), highlighting the synchronicity between photomodulation of $G^{\prime}$ and kinetics of 35 photoisomerization. The origin of the time was set at the beginning of the first irradiation cycle. c) Solvent exchange (water $\rightarrow$ DMSO) experiment and 36 d) subsequent measurement of $G^{\prime}$, which was not affected by irradiation with the green or blue LEDs.

The evolution of the moduli over time was measured at a frequency of $10 \mathrm{~Hz}$ with three different samples. The initial value of $G^{\prime}$ was found to be constant for all samples, at around $375 \mathrm{~Pa}$ (corresponding to a cross-linking density of $\approx 150 \mathrm{mmol} \mathrm{m} \mathrm{m}^{-3}$; see the Supporting Information), indicating the reproducibility of the synthesis procedure. Upon irradiation with green light, $G^{\prime}$ decreased and stabilized after 2 min, while subsequent irradiation with blue light quickly restored the initial elasticity (see Figure 3a). Both green and blue-lightirradiated states could be kept with stable $G^{\prime}$ values for a few minutes after the light was switched off. However, a slight increase of $G^{\prime}$ was observed over time for both states, possibly due to small changes in the swelling of the gel during isomerization. Several switching cycles could be performed alternating between cross-linking density without exhibiting any fatigue. Remarkably, photomodulation of the mechanical properties occurred at the same speed as photoisomerization within the gel (i.e., the value of $G^{\prime}$ stabilized as soon as the PSS was reached; see Figure 3b).

In order to understand the mechanism of the photomodulation of $G^{\prime}$, the gel's mechanical properties were also investigated in an organic solvent. Exchanging the swelling 39 agent (water) with DMSO causes tremendous swelling of the 40 sample, as the diameter increased from 20 to $27 \mathrm{~mm}$, the 41 thickness increased from 0.6 to $0.7 \mathrm{~mm}$ (see Figure 3c), and 42 the gel became much more elastic ( $G^{\prime}$ of $170 \mathrm{~Pa}$ in DMSO vs 43 $375 \mathrm{~Pa}$ in water; see Figure $3 \mathrm{~d}$ ). In addition, no photomodu- 44 lation of $G^{\prime}$ could be observed in the DMSO sample. In view 45 of these last experiments, it is assumed that the photomod- 46 ulation of $G^{\prime}$ occurring in the hydrogel arises from revers- 47 ible disruption of noncovalent interactions between F-azos 48 in water. Since E-azobenzenes are planar and more hydro- 49 phobic than the Z-isomers (see Figure 4), their tendency to 50 assemble (via $\pi$-stacking and hydrophobic effects) is higher, 51 especially in water. ${ }^{[16]}$ As a result, E-isomers most likely act 52 as noncovalent additional cross-linkers, leading to less elastic 53 hydrogels, while $E \rightarrow Z$ isomerization could disrupt these 54 physical cross-links hence softening the gel. By contrast, the 55 organogel swollen with DMSO does not exhibit any change 56 in $G^{\prime}$ upon irradiation because the physical cross-links 57 induced by the hydrophobicity of the E-azo moiety in water 58 readily dissociate in the organic solvent. The disruption of 59 
3<smiles>c1ccc(N=Nc2ccccc2)cc1</smiles><smiles>Fc1cccc(F)c1N=Nc1c(F)cccc1F</smiles>

1

2<smiles>CNC(=O)c1cc(F)c(N=NNc2c(F)cc(C(=O)NC)cc2F)c(F)c1</smiles><smiles>CNC(=O)c1ccc(N=Nc2ccc(C(=O)NC)cc2)cc1</smiles>

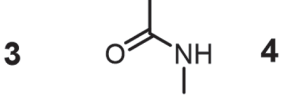

\begin{tabular}{|c|c|c|c|c|c|}
\hline 1 & 0.0 & 4.5 & 4.5 & 0.1 & 51.4 \\
\hline 2 & 0.4 & 7.4 & 7.0 & 30.2 & 58.2 \\
\hline $\begin{array}{c}3 \\
\left(3^{\prime}\right)\end{array}$ & $\begin{array}{c}4.6 \\
(8.4)\end{array}$ & $\begin{array}{c}9.0 \\
(8.6)\end{array}$ & $\begin{array}{c}4.4 \\
(0.2)\end{array}$ & $\begin{array}{c}31.1 \\
(31.1)\end{array}$ & $\begin{array}{c}58.0 \\
(58.0)\end{array}$ \\
\hline $\begin{array}{c}4 \\
\left(4^{\prime}\right)\end{array}$ & $\begin{array}{c}0.6 \\
(9.4)\end{array}$ & $\begin{array}{c}4.6 \\
(7.9)\end{array}$ & $\begin{array}{c}4.0 \\
(1.5)\end{array}$ & $\begin{array}{c}1.8 \\
(1.8)\end{array}$ & $\begin{array}{c}50.0 \\
(50.0)\end{array}$ \\
\hline
\end{tabular}

Figure 4. Dipole moments $(\mu)$ and CCNN dihedral angles $(\Phi)$ of compounds $1-4$, computed at the B $3 L Y P / 6-311+G(d, p)$ level of theory. Compounds 3 and $\mathbf{4}$ can display alternative stable conformations, where the two amido groups point toward the same direction (referred to as $\mathbf{3}^{\prime}$ and $\mathbf{4}^{\prime}$; see the corresponding values in parentheses). Dipole moments are given in debye (D) and dihedral angles in degrees $\left({ }^{\circ}\right)$.

secondary physical cross-links can also explain the large expansion of the gel during solvent exchange (Figure 3c) in addition to a higher affinity of the network for DMSO than for water.

Although the hydrogels described here display significant (yet moderate) photomodulation of elasticities, we did not observe any concomitant macroscopic contraction-expansion motion as reported recently ${ }^{[16]}$ in PEG hydrogels of similar architecture incorporating parent (nonfluorinated) azobenzenes (see compound 4; Figure 4), which might be due to different association tendency of the photochromic moieties. Three driving forces can be involved in the association of amidoazobenzenes in water: hydrogen bonds, hydrophobic effects, and $\pi$-stacking. Although it is difficult to evaluate differences in H-bonding ability between F-azos and parent azobenzenes, it is possible to gain insight into $\pi$-stacking ability by comparing their deviation from planarity, and into hydrophobic interactions by comparing their dipole moments $(\mu)$. The minimum geometries and dipoles of a series of relevant azobenzenes were computed using density functional theory (DFT; see Figure 4). According to the calculations, plain E-azobenzene as well as its amido derivative (compounds 1 and $\mathbf{4}$ ) is nearly planar, whereas E-F-azos (compounds 2 and 3) exhibit significant deviation from planarity (CCNN twist angle of $\approx 30^{\circ}$ for the minimum geometry of the E-isomers; see Figure 4 and Figure S4, Supporting Information). ${ }^{[25]}$ Consequently, the $\pi$-stacking ability of the E-isomer should be weakened, supporting the moderate 34 photomodulation observed in F-azos as well as the absence of 35 photoinduced macroscopic motion. As a consequence of the 36 less planar geometry, the calculated dipoles for the E-isomers 37 of F-azos are higher compared to parent azobenzenes (see 38 Figure 4), hence weakening hydrophobic effects in the hydro- 39 gels. A last reason for the different observed behaviors could 40 be a smaller difference of dipole moments between $E$ and 41 $Z$-isomers $(\Delta \mu)$ for F-azos, which would affect the amplitude 42 of the swelling/deswelling of the hydrogels. Nevertheless, DFT 43 calculations indicate that $\Delta \mu$ are similar for compounds 3 and $4 ; \quad 44$ hence, at this stage, we believe that the system could be opti- 45 mized mainly via planarization of the visible-light responsive 46 moiety.

\section{Conclusions}

Hydrogels whose elasticity can be reversibly phototuned with 52 visible light have been presented. The use of UV light could 53 be avoided, which is generally beneficial regarding the pho- 54 tostability of the materials and their surroundings as well 55 as their future use for biological applications. The origin of 56 the light-induced responses is attributed to the disruption of 57 secondary physical cross-links between photochromic moie- 58 ties upon isomerization, as inferred by solvent exchange in 59 
DMSO, which in addition to suppressing any photoreponses induces a large expansion of the samples. DFT calculations have been performed to gain insight into the association tendency of F-azobenzenes, revealing significant deviation from planarity for the E-isomers, which is detrimental to the formation of noncovalent crosslinks. Optimizing the design of F-azobenzenes regarding their planarity, for example, employing only one ortho-F per phenyl ring, could increase the amplitude of $G^{\prime}$ phototuning and possibly induce macroscopic motion of the materials for the preparation of synthetic macromolecular machines. ${ }^{[26]}$

\section{Supporting Information}

Supporting Information is available from the Wiley Online Library or from the author.

\section{Acknowledgements}

Generous support from the German Research Foundation (DFG, through research grants BL1269/1-1 and BL1269/1-3) is gratefully acknowledged.

\section{Conflict of Interest}

The authors declare no conflict of interest.

\section{Keywords}

azobenzenes, hydrogels, photodynamic materials, visible light

Received: August 2, 2017 Revised: September 29, 2017 Published online:

[1] D. Seliktar, Science 2012, 336, 1124.

[2] M. Zhong, R. Wang, K. Kawamoto, B. D. Olsen, J. A. Johnson, Science 2016, 353, 1264.
[3] A. J. Engler, S. Sen, H. L. Sweeney, D. E. Discher, Cell 2006, 126, 1 677.

[4] A. M. Rosales, K. S. Anseth, Nat. Rev. Mater. 2016, 1, 15012.

[5] S. Chaterji, I. K. Kwon, K. Park, Prog. Polym. Sci. 2007, 32, 1083.

[6] A. M. Kloxin, A. M. Kasko, C. N. Salinas, K. S. Anseth, Science 2009, 324, 59.

[7] K. Sumaru, M. Kameda, T. Kanamori, T. Shinbo, Macromolecules 2004, 37, 4949.

[8] J. ter Schiphorst, S. Coleman, J. E. Stumpel, A. Ben Azouz, 8 D. Diamond, A. P. H. J. Schenning, Chem. Mater. 2015, 27, 9 5925.

[9] M. Irie, D. Kunwatchakun, Macromolecules 1986, 19, 2476.

[10] S. Yamaguchi, S. Matsumoto, K. Ishizuka, Y. Iko, K. V. Tabata, 12 H. F. Arata, H. Fujita, H. Noji, I. Hamachi, Chem.—Eur. J. 2008, 14, 13 1891.

[11] Y.-L. Zhao, J. F. Stoddart, Langmuir 2009, 25, 8442.

[12] S. Tamesue, Y. Takashima, H. Yamaguchi, S. Shinkai, A. Harada 15 Angew. Chem., Int. Ed. 2010, 49, 7461.

[13] D. Wang, M. Wagner, H.-J. Butt, S. Wu, Soft Matter 2015, 11, 17 7656.

[14] T. Ikeda, M. Nakano, Y. Yu, O. Tsutsumi, A. Kanazawa, Adv. Mater. 19 2003, 15, 201.

[15] N. Hosono, M. Yoshikawa, H. Furukawa, K. Totani, K. Yamada, 21 T. Watanabe, K. Horie, Macromolecules 2013, 46, 1017.

[16] K. Iwaso, Y. Takashima, A. Harada, Nat. Chem. 2016, 8, 625.

[17] Q. Li, G. Fuks, E. Moulin, M. Maaloum, M. Rawiso, I. Kulic, 23 J. T. Foy, N. Giuseppone, Nat. Nanotechnol. 2015, 10, 161.

[18] J. T. Foy, Q. Li, A. Goujon, J.-R. Colard-Itté, G. Fuks, E. Moulin, 25 O. Schiffmann, D. Dattler, D. P. Funeriu, N. Giuseppone, Nat. 26 Nanotechnol. 2017, 12, 540.

[19] A. M. Rosales, K. M. Mabry, E. M. Nehls, K. S. Anseth, Biomacro- 28 molecules 2015, 16, 798.

[20] D. Bléger, S. Hecht, Angew. Chem., Int. Ed. Engl. 2015, 54, 11338.30

[21] D. Bléger, J. Schwarz, A. M. Brouwer, S. Hecht, J. Am. Chem. Soc. 31 2012, 134, 20597.

[22] C. Knie, M. Utecht, F. Zhao, H. Kulla, S. Kovalenko, A. M. Brouwer, 33 P. Saalfrank, S. Hecht, D. Bléger, Chem. Eur. J. 2014, 20, 16492.

[23] M. F. Debets, S. S. van Berkel, S. Schoffelen, F. P. J. T. Rutjes, 35 J. C. M. van Hest, F. L. van Delft, Chem. Commun. 2010, 46, 97.

[24] M. Chen, Y. Gu, A Singh, M. Zhong A. M Jordan, S. Biswas, 36 L. T. J. Korley, A. C. Balazs, J. A. Johnson, ACS Cent. Sci. 2017, 3, 37 124.

[25] Note that in a single crystal the F-azo moiety was found to be 39 essentially planar, see ref. (22).

[26] Macromol. Rapid Commun. 2018.

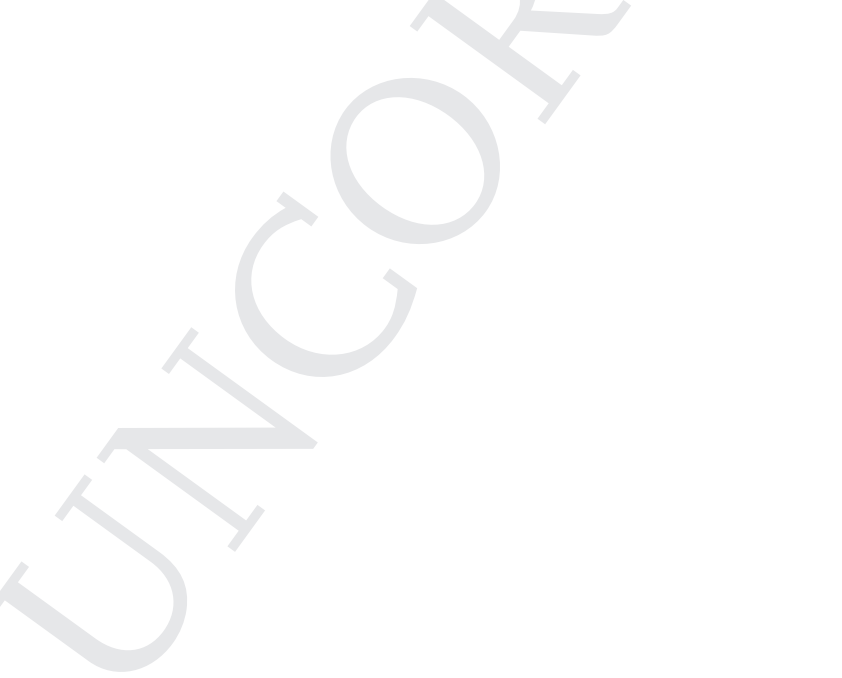


Query

Q1: Please provide TOC keyword.

Q2: Please provide the highest academic title (either Dr. or Prof.) for all authors, where applicable.

Q3: Please define 'LED' at the first occurrence in the text.

Q4: Please define 'DMF' at the first occurrence in the text.

Q5: Please define 'DMSO' at the first occurrence in the text.

Q6: Please define 'CCNN' at the first occurrence in the text.

Q7: Please provide author names, volume number and page number for ref. (26), if available now. 
Macromolecular

\section{Rapid Communication}

Macromolecular

Journals

\section{Reprint Order Form 2017}

\section{Short DOI: marc.}

Please send me and bill me for

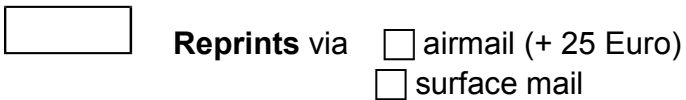

Please send me and bill me for a:

Issue copies (25 Euro)

high-resolution PDF file (330 Euro).

My Email address:

Please note: It is not permitted to present the PDF file on the internet or on company homepages.

\section{Information regarding VAT}

Please note that from German sales tax point of view, the charge for Reprints, Issues or Posters is considered as "supply of goods" and therefore, in general, such delivery is a subject to German sales tax. However, this regulation has no impact on customers located outside of the European Union. Deliveries to customers outside the Community are automatically tax-exempt. Deliveries within the Community to institutional customers outside of Germany are exempted from the German tax (VAT) only if the customer provides the supplier with his/her VAT number. The VAT number (value added tax identification number) is a tax registration number used in the countries of the European Union to identify corporate entities doing business there. It starts with a country code (e.g. FR for France, GB for Great Britain) and follows by numbers.

\section{VAT no.:}

(Institutes / companies in EU countries only)

Purchase Order No.:
Editorial Office:

Wiley-VCH Verlag

Boschstraße 12, 69469 Weinheim

Germany

Tel.: $\quad+49(0) 6201-606-581$

Fax: +49 (0) $6201-606-510$

Email: macromol@wiley-vch.de

Delivery address / Invoice address:

Name of recipient, University, Institute, Street name and Street number, Postal Code, Country

Date and Signature:

Credit Card Payment (optional) - You will receive an invoice.

VISA, MasterCard, AMERICAN EXPRESS

Please use the Credit Card Token Generator located at the website below to create a token for secure payment. The token will be used instead of your credit card number.

Credit Card Token Generator:

https://www.wiley-vch.de/editorial production/index.php

Please transfer your token number to the space below.

Credit Card Token Number

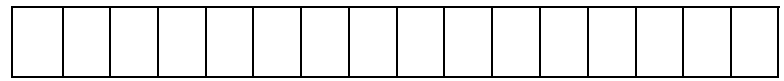

Price list for reprints (The prices include mailing and handling charges. All Wiley-VCH prices are exclusive of VAT)

\begin{tabular}{|c|c|c|c|c|c|c|}
\hline No. of pages & 50 copies & 100 copies & $\begin{array}{l}\text { Price (in El } \\
150 \text { copies }\end{array}$ & $\begin{array}{l}\text { for orders of } \\
200 \text { copies }\end{array}$ & 300 copies & 500 copies \\
\hline $1-4$ & 345 & 395 & 425 & 445 & 548 & 752 \\
\hline $5-8$ & 490 & 573 & 608 & 636 & 784 & 1077 \\
\hline $9-12$ & 640 & 739 & 786 & 824 & 1016 & 1396 \\
\hline $13-16$ & 780 & 900 & 958 & 1004 & 1237 & 1701 \\
\hline $17-20$ & 930 & 1070 & 1138 & 1196 & 1489 & 2022 \\
\hline $\begin{array}{c}\text { for every additional } 4 \\
\text { pages }\end{array}$ & 147 & 169 & 175 & 188 & 231 & 315 \\
\hline
\end{tabular}

Wiley-VCH Verlag GmbH \& Co. KGaA; Location of the Company: Weinheim, Germany;

Trade Register: Mannheim, HRB 432833, Chairman of the Board: Mark Allin

General Partner: John Wiley \& Sons $\mathrm{GmbH}$, Location: Weinheim, Germany

Trade Register Mannheim, HRB 432296, Managing Director: Sabine Steinbach 